\title{
Nexus between perceived job insecurity and employee work-related outcomes amid COVID-19: Attenuating effect of supervisor
} support

\author{
Shuaib Ahmed Soomro* \\ Sukkur IBA University, Sukkur, Pakistan
}

Received 26 November 2020

Accepted 29 January 2021

\begin{abstract}
.
OBJECTIVE: This study aims to examine perceived job insecurity as an antecedent of adverse psychological well-being and job outcomes (i.e., job satisfaction and organizational commitment), applying conservation of resources and organizational support theories. The study also investigated the role of perceived supervisor support as a moderator in the study.

METHODS: Two-wave longitudinal data $(n=385)$ was collected with two months between Time 1 and Time 2 . Data collected from employees working in two MNCs in Pakistan. A conceptual framework was developed where the mediating role of work stress on the job insecurity relationship is conditional to the values of job satisfaction and organizational commitment. RESULTS: During analysis, a positive association was found between job insecurity and work stress. Further, job insecurity led to work stress and it negatively led to job satisfaction and organizational commitment. Perceived supervisor support moderated work stress and job satisfaction and organizational commitment. The moderated mediation results indicate that supervisor support moderated the indirect effect of job insecurity on work outcomes.

CONCLUSION: This paper examines the relationship between job insecurity and employee work outcomes amidst COVID19. The findings have significant implications for employers and employees. Moreover, study findings expand our knowledge of COR theory and Organizational support theory for MNCs employees in the COVID-19 pandemic.
\end{abstract}

Keywords: Job insecurity, psychological well-being, supervisor support, job satisfaction, organizational commitment COVID-19

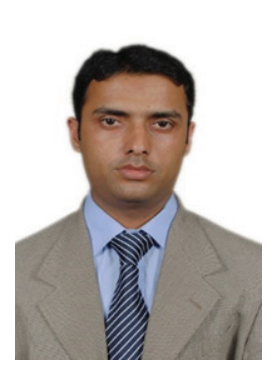

Dr. Shuaib Ahmed Soomro is a Assistant Professor of $\mathrm{HRM} / \mathrm{OB}$ at Sukkur IBA University. He holds a $\mathrm{Ph} . \mathrm{D}$. in HRM and OB from IAE AixMarseille University, France. Main research interests include psychology, organizational behavior, and HRM practices. ORCID ID: https://orcid. org/0000-0003-0849-8942
*Corresponding author: Shuaib Ahmed Soomro, Sukkur IBA University, Sukkur, Pakistan. E-mail: shuaib.ahmed@iba-suk.edu. pk. ORCID ID: https://orcid.org/0000-0003-0849-8942

\section{Introduction}

COVID-19 pandemic has been triggered stress of perceived job insecurity (JI) and anticipated job loss among workers in various sectors of the economy $[1,2]$. It is because of the impact of the pandemic that caused significantly on the economy and workforce. Due to the pandemic situation and its quick spread, world health organization suggested distancing standard operating procedures, so that virus transference speed slows down. The pandemic situation and the spread of the virus caused many countries worldwide to close non-essential 
businesses and implement stay-at-home orders. Studies show that COVID-19 increased unemployment and caused workers well-being and they have psychological disorders [3-6]. Considering the adverse consequences of the COVID-19 and unemployment, impact on the employment situation and financial stability originate from the roots of COVID-19 that have significantly contributed to the increased rates of stress and burnout.

Job insecurity is a stressful experience that positively relates to distress and adverse feelings [7]. It is often measured by asking employees to indicate their perceived likelihood of losing their job [6]. Job insecurity is defined as the perception that the future of one's job is unstable or at risk [8]. The real threat of job loss depends on the perception of the worker going through the process. Although research has revealed that subjective perceptions of JI are more closely linked to employees' work health and psychological outcomes [9-11]. A small extent of research has analyzed possible psychological implications of the job insecurity during pandemics. However, recent studies have shown an increase in stress concerning job insecurity because of pandemic [12]. For instance, in the course of the severe acute respiratory syndrome (SARS) breakout, it causes psychological disorders, an increase in stress level and perceived job among respondents [13]. Similarly, the COVID-19 significantly caused variations in employment across the world, and workers experienced increased job insecurity, which may be associated with lowered well-being.

Job insecurity process is cyclical in nature. For instance, a worker who perceives job insecurity reacts to it and changes his attitude and behaviour. Findings of many studies significantly support that due to COVID-19 people experienced more significant job concerns and were negatively related to job attitude and well-being [14]. The behavioural outcomes include lesser job satisfaction, lower organizational commitment [15], lack of trust in management, higher intentions to leave [5, 16, 17]. All the behavioural outcomes can impact organizational well-being and negatively affect organizational characteristics, leading further to insecurity among workers $[4,18,19]$. Hence, it is a cycle, and it can be a vicious if it gets out of control.

Previous research shows that job insecurity causing mental health, particularly during periods of crisis. In this study, we aim to examine perceived job insecurity as an antecedent of adverse job outcomes i.e. job satisfaction (JS) [20] and organizational commit- ment (OC) [21] by using conservation of resources theory (COR) and organizational support theory. We analyze the role of supervisor support as a possible coping mechanism. Based on the COR [22], we argue that employees feel work stress when there is a threat of resource loss (perceived job loss), which turn an employee to recover from a resource loss. In brief, we argue that job insecurity can lead to stress, affecting employee job outcomes, while workers receiving supervisor support [23] as a resource gain as an individual characteristic makes them less sensitive to perceived job insecurity.

Pandemic has adversely affected MNCs performance and employment sector globally. In this regard our study offers some possible contributions; first, the present research contributes to the COR theory and Organization support theory by providing further insight into the relationship between job insecurity, work stress (WS), the role of supervisor support and work outcomes over time. COR theory explains, the development of stress when there is a loss of resources or threat of loss of resources in the form of job insecurity in COVID-19. The pandemic situation is threatening employees resources. It is a possible contribution that adds to the COR theory. Organizational support theory provides a valuable lens to study employees' trade outcomes and work efforts to cope with the threatening position in the same settings. For this, we led a longitudinal survey (two-wave) among employees employed in MNCs in Pakistan. Secondly, we investigate the relationship between JI and the role of supervisor support. Based on the literature review, the research to date has yet to test the relationship among above factors over time, thus contributing to the development of a more comprehensive understanding of job insecurity and employee psychological well-being in COVID-19 times.

\section{Literature review and hypotheses development}

COR theory argues that worker obtains resources to sustain in the workplace [24]. It describes workers make efforts to obtain, maintain, and protect their resources to avoid stress in critical times such as COVID-19 pandemic. As a stress theory, COVID-19 is a critical situation that causes anxiety and depression among people as it threatens their resources. It provides a lens to study individual psychological well-being and job outcomes in COVID-19 pandemic. The COR theory focuses on 'stress' level of an 
individual and it explains both loss and gain cycles. It holds that both cycles are for individuals facing stress and they stand against it in critical times. The COR theory holds stress conceived is experienced in three steps; first, when there is a threat of a loss of resources, second, an actual net loss of resources and third, a lack of gained resources next to the spending of resources.

While organizational support assumes that supportive leadership significantly reduces the perceived uncertainties, it leads to crises among workers [25]. It predicts that supportive leadership protects employees from the harmful effects of stressful events; the approach also assumes by influencing what employees think about and how they cope with the situation $[26,27]$. Organizational support refers to providing psychological and material resources intended to benefit an individual's capacity to cope with stress $[25,28]$. While, leadership is considered the primary source of support for employees because they are able to provide rewards, protect, and motivate in times of crises such as COVID-19 [29-31]. For this reason, the authority of the supervisor in providing essential resources and information to employees can play a supportive role in reducing the perceived uncertainties of employees regarding the impacts of a crisis $[32,33]$.

\subsection{The COVID-19, job insecurity and job outcomes}

$\mathrm{JI}$ is conceptualized as a subjective phenomenon [34]. Greenhalgh and Rosenblatt [35] characterized $\mathrm{JI}$ as "perceived powerlessness to maintain desired continuity in a threatened job situation. It is based on the individual's interpretation of the immediate work environment and perception regarding that environment. It indicates a subjectively appraised source through cognitive and perceptual process [36, 37].

Research has identified three primary sources of JI that impact the relationship between JI and job outcomes. These are distinct types of stressors i.e. socio-economic conditions, organizational characteristics, and individual characteristics [5, 18, 36, 38]. These are stressors that lead to the stress of perceived $\mathrm{JI}$ and anticipated job loss.

Socio-economic change are concerned with mass layoff i.e. unemployment rate in an economy [39]. It is the economic change of the country at a macro level where people lose their jobs. Organizational characteristics are related to the performance or the losses of the organization. An official announcement of layoffs at the organizational level $[40,41]$, not like socioeconomic where massive layoffs occurs across the country. Organizational layoffs may occur because of an upcoming merger or acquisition or a result of restructuring or downsizing [39]. New technology and automation in the organization eliminate workers and there are massive layoffs across the organization at various levels. As stated above, economic changes in the country has an impact on the organizational performance, it causes workers and they lose their jobs.

Further, the pandemic situation also leads workers to perceive job insecurity. For instance, workers perceive in these situations that their job is at risk in the organization. For example, if an employee working at a restaurant and no customer come in, the worker will panic how long this situation will last. In the prevailing conditions, it makes employees perceive losing a job and become sick, feeling uncomfortable. It causes stress to them about their job or losing the desired characteristics.

The COVID-19 pandemic is a situation that has significantly affected economies and various sectors around the globe [12, 13, 42]. On account of the unusual time like COVID-19 there is a process of closing various organizations globally, affecting workers and losing their jobs in return (for example, please see; DePietro, 2020; Sahu, 2020). As the effects of the pandemic and containment measures hit economies, millions of people have been unable to go to work, resulting in an exceptionally stark drop-in activity and unprecedented job losses. Up to 10 times fewer hours were worked in some countries, compared with the first few months of the 2008 financial crisis. While millions have been pushed to reduced hours, millions of others have lost their jobs entirely, with little improvement in sight as the pandemic is continuously hitting the masses around the world (OECD).

Prior research on job insecurity is linked to uncertainty, anxiety and stress that leads to lower job satisfaction, organizational commitment, lesser attachment to the organization and other adverse outcomes [5, 16, 39, 44]. Therefore, we argue that employees who feel the threat of losing their jobs in COVID-19 pandemic will experience higher stress and it further leads to lower job satisfaction, organizational commitment and job performance. Thus, we hypothesize the following.

Hypothesis 1: Job insecurity significantly lead to employee work stress in COVID-19 pandemic. 


\begin{abstract}
Hypothesis 2: Work stress negatively lead to employee a) job satisfaction, b) organizational commitment in COVID-19 pandemic.
\end{abstract}

Hypothesis 3: Supervisor support positively lead to a) job satisfaction, b) organizational commitment in COVID-19 pandemic.

\subsection{Role of supportive leadership}

It is proposed that COVID-19 pandemic crises can be alleviated by supportive leadership. Supportive leadership indicates the degree to which subordinates receive support from their leadership [23, 33, 45]. Supportive leadership support reflects the employees' perception of the quality of their relationship with supervisors [46]; and it represents the degree to which employees realize that their leadership cares about their concerns and well-being [47, 48]. Existing research shows that supportive leadership plays a significant role in sustaining attitudes and motivate employee in crises [49-51]. More precisely, supportive leadership is essential in sustaining employees' work morale and psychological well-being during a time of crisis [52]. For instance, Chen et al., [28], based on the case of flexible manufacturing enterprises in China revealed that the organizational support has a significant positive effect on the workers' well-being in a critical situation.

From the theoretical perspective, supportive leadership protects employees from the harmful effects and other stressful events; the approach also assumes by influencing what employees think about and how they cope with the situation [26, 27]. Organizational support refers to a provision of psychological and material resources intended to benefit an individual's capacity to cope with stress [25, 28]. Leadership is considered the primary source of support for employees because they are able to provide rewards, protection, encouragement, and motivation to employees [29-31]. Leadership also support employees by providing information that eases their concerns about uncertainties [53]. This idea is kept in the study of Charoensukmongkol et al., (2016), which found that the quality of the relationship that employees develop with their immediate supervisors plays a crucial role in reducing employees' workplace uncertainty. For this reason, the authority of the supervisor in providing essential resources and information to employees can play a critical supporting role in reducing the perceived uncertainties of employees regarding the impacts of a crisis [32, 33].
H4: Supportive leadership will moderate the relationship between work stress and a) job satisfaction, b) organizational commitment. The conditional positive relationship between perceived job insecurity and stress is stronger among those with low supervisor support compared with those high in support.

\section{Methodology}

Data was collected from two multinational companies (MNCs) in Pakistan. Both companies are doing business in food and beverages sectors. We collected two-wave longitudinal data from part-time workers after two months of lag-time between $\mathrm{T} 1$ and $\mathrm{T} 2$. The two-wave longitudinal design has continued to dominate the research scene [54]. Dormann and Zapf [55], found that it took at least two-wave for the longitudinal effects of stressors at work on worker's well-being.

The survey was conducted in MNCs having a layoff process in COVID-19 pandemics. At the same time, a pen and pencil survey were used to collect data. At the beginning of the study, participants received a cover letter in the English language as it is country's official language and consistently used by other researchers using Pakistani samples (e.g., De Clercq et al., 2021; Kundi et al., 2020). The participants were told about the purpose and assured confidentiality of the data. They were also informed about the longitudinal nature of the study and were asked to mention their email address at $\mathrm{T} 1$ so they can be contacted again to get $\mathrm{T} 2$ data after two months.

We used convenience sampling method for our data collection. In the pandemic situation, MNCs were reluctant to provide employees downsizing data. So we used our references and it was drawn from the companies that are close to us. We distributed total 1200 survey questionnaires to the employees. Each questionnaire was assigned an identification code that enabled to link responses from the two-stages without the need for participants' names. The first wave of data collection at $\mathrm{T} 1$ resulted in 455 questionnaires (response rate of $38 \%$ ) and the second wave (T2), two months later, 400 responses (response rate of 33\%). We used SPSS and checked how many observations in our data has issues. In the beginning, preliminary diagnosis of variables helps us to avoid this problem, We tried to check the number of valid observations included in the analysis is sufficient. We conducted a dropout analysis to evaluate whether the dropout at T2 
was selective (cf. Goodman \& Blum, 1996). We found no significant differences between the respondents and the non-respondents at $\mathrm{T} 2$ concerning variables. After the dropout, the final sample consisted of 385 valid questionnaires (response rate of $32 \%$ ). On average, the final selection resulted in $56 \%$ men, they were 35 years old and had a mean experience of 7 years.

\subsection{Job insecurity}

De Witte [19] 4-item scale was used to measure the JI. Example, item includes "I feel insecure about the future of my job". The Cronbach Alpha measurement for the JI reliability scale was ( 0.93$)$ for $\mathrm{T} 1$ and $(0.83)$ $\mathrm{T} 2$ thus indicating strong rating reliability among the raters. All measures were set to a 5-point Likert scale ranging from $1=$ Strongly disagree to $5=$ Strongly Agree.

\subsection{Work stress}

Netemeyer, Maxham and Pullig [57] 4-item scale was used to measure WS. A sample item is "I feel nervous because of my job" The Cronbach Alpha measurement for the job stress scale was (0.94) for $\mathrm{T} 1$ and $(0.78)$ for $\mathrm{T} 2$ thus indicating strong rating reliability among the raters.

\subsection{Organizational support}

It measures employees' perception regarding the firm care and support and appreciation of their valuable contribution. It is measured with four-items used in the studies of Eisenberger et al., [23]. Sample item includes The sample item includes, "I can expect recognition by top management when I make an outstanding contribution," "My supervisor respects my contributions," and "Top management trusts us to make the right decisions." The Cronbach Alpha measurement for the scale was $(0.90)$ for $\mathrm{T} 1$ and $(0.85)$ for $\mathrm{T} 2$.

\subsection{Job satisfaction}

Luthans [58] 5-item scale was used to measure the JS. Example item includes "for me this is the best of all possible organizations for which to work" The Cronbach Alpha measurement for the JS scale was ( 0.83$)$ for $\mathrm{T} 1$ and $(0.84)$ for $\mathrm{T} 2$ thus indicating strong rating among the raters.

\subsection{Organizational commitment}

Allen and Mayer [59] three items scale was used to measure the OC. Example item includes "I really care about the fate of this organization". The Cronbach Alpha measurement for the organizational scale was (0.87) for T1 and (0.86) for T2 thus indicating strong rating reliability among the raters.

\subsection{Control variables}

We control the influence of gender $(1=$ male, $2=$ female), age (in years), and organizational tenure (assessed in years) as they are considered as covariates in previous research (e.g., Moksnes and Espnes 2013; Schulze and Pohl 2020). More specifically, it is argued that older workers may need more support and may be affected by work stress at different times [36, 37]. Therefore, we controlled for the affected age and gender that might have on the relationships that we are investigating in the study. The data were analyzed using SPSS version 22.

\section{Results}

Table 1 shows the correlation among the study variables along with their mean and standard deviation.

\subsection{Test of common method Bias}

As the study variables were self-rated, so the issue of common method variance $(\mathrm{CMV}$; the amount of spurious correlation between variables measured using the same method; Kundi et al., 2020, p.7) was of concern. Thus, we addressed the issue of CMV through both procedural and statistical remedies. As mentioned earlier, we adopted procedural remedies such as clearly stating survey instructions, providing detailed information on the purpose of the study, and assuring confidentiality and anonymity of participant responses. Moreover, it was clearly noted that participation was voluntary. Statistically, we conducted Harman's single-factor test to check the presence of common method bias [63]. Results showed that a single factor was extracting less than $50 \%$ of the total variance, so there was no common method bias in it. For hypotheses testing, we used hierarchal regression. 
Table 1

Mean, Standard Deviation, Correlations and Reliability coefficients on diagonal

\begin{tabular}{|c|c|c|c|c|c|c|c|c|c|c|c|c|}
\hline Variables & Mean & SD & 1 & 2 & 3 & 4 & 5 & 6 & 7 & 8 & 9 & 10 \\
\hline $1 \mathrm{JI}(\mathrm{T} 1)$ & 2.42 & 1.14 & 0.93 & & & & & & & & & \\
\hline 2. Perceived stress (T1) & 2.51 & 1.19 & $0.915^{* *}$ & 0.94 & & & & & & & & \\
\hline 3. JS (T1) & 2.95 & 0.97 & -0.051 & -0.092 & 0.83 & & & & & & & \\
\hline 4. OC (T1) & 3.05 & 1.15 & -0.058 & $-0.113^{* *}$ & $0.835^{* *}$ & 0.87 & & & & & & \\
\hline 5. Organizational support (T1) & 3.10 & 0.59 & 0.068 & 0.086 & $0.243^{* *}$ & $0.266^{* *}$ & 0.90 & & & & & \\
\hline 6. JI (T2) & 3.25 & 0.96 & 0.092 & 0.096 & $-0.307^{* *}$ & $-0.274^{* *}$ & $0.567^{* *}$ & 0.83 & & & & \\
\hline 7. Perceived stress (T2) & 3.35 & 0.64 & 0.024 & 0.023 & $-0.308^{* *}$ & $-0.259^{* *}$ & $0.750^{* *}$ & $0.555^{* *}$ & 0.78 & & & \\
\hline 8. JS (T2) & 2.88 & 0.94 & -0.023 & -0.018 & $0.677^{* *}$ & $0.502^{* *}$ & $0.176^{* *}$ & $-0.263^{* *}$ & $-0.283^{* *}$ & 0.84 & & \\
\hline 9. OC (T2) & 3.01 & 1.15 & -0.056 & -0.093 & $0.960^{* *}$ & $0.845^{* *}$ & $-0.271^{* *}$ & $-0.292^{* *}$ & $-0.277^{* *}$ & $0.517^{* *}$ & 0.86 & \\
\hline 10 Supervisor support (T2) & 3.05 & 0.71 & $0.275^{* *}$ & $0.310^{* *}$ & $0.254^{* *}$ & $0.310^{* *}$ & $0.860^{* *}$ & $0.418^{* *}$ & $0.601^{* *}$ & $0.221^{* *}$ & $0.255^{* *}$ & 0.85 \\
\hline
\end{tabular}

$\mathrm{N}=385$, Correlations is significant at ${ }^{*} p<0.05^{* *} p<0.01^{* * *} p<0.01$.

Table 2

Results of direct hypotheses at $\mathrm{T} 1$ and $\mathrm{T} 2$

\begin{tabular}{|c|c|c|c|c|c|c|}
\hline \multirow[t]{2}{*}{ Time 1} & \multicolumn{2}{|c|}{$\begin{array}{l}\text { Work stress } \\
\text { (WS) }\end{array}$} & \multicolumn{2}{|c|}{$\begin{array}{c}\text { Job satisfaction } \\
(\text { JS })\end{array}$} & \multicolumn{2}{|c|}{$\begin{array}{c}\text { Organizational } \\
\text { commitment (OC) }\end{array}$} \\
\hline & $B$ & $S E$ & $B$ & $S E$ & $B$ & $S E$ \\
\hline Job insecurity & $0.885^{*}$ & 0.033 & $-0.353^{* *}$ & 0.053 & $-0.465^{*}$ & 0.055 \\
\hline Work stress & & & $-0.370^{* *}$ & 0.057 & $-0.549^{*}$ & 0.050 \\
\hline Organizational support & & & $0.957^{*}$ & 0.098 & $0.552^{* *}$ & 0.100 \\
\hline Organizational support x WS & & & $0.068^{*}$ & 0.040 & $0.053^{*}$ & 0.036 \\
\hline $\mathrm{R}^{2}$ & & & & & & \\
\hline$\underline{F}$ & & & & & & \\
\hline \multirow[t]{2}{*}{ Time 2} & \multicolumn{2}{|c|}{$\begin{array}{l}\text { Work stress } \\
\text { (WS) }\end{array}$} & \multicolumn{2}{|c|}{$\begin{array}{c}\text { Job satisfaction } \\
(\text { JS }) \\
\end{array}$} & \multicolumn{2}{|c|}{$\begin{array}{c}\text { Organizational } \\
\text { commitment (OC) }\end{array}$} \\
\hline & $B$ & $S E$ & $B$ & $S E$ & $B$ & $S E$ \\
\hline Job insecurity & $0.233^{* *}$ & 0.054 & $-0.412^{*}$ & 0.037 & $-0.376^{*}$ & 0.060 \\
\hline Work stress & & & $-0.452^{*}$ & 0.098 & $-0.678^{*}$ & 0.102 \\
\hline Organizational support & & & $0.397^{*}$ & 0.085 & $0.649^{*}$ & 0.087 \\
\hline Organizational support x WS & & & $0.0071^{*}$ & 0.0501 & $0.068^{*}$ & 0.0450 \\
\hline $\mathrm{R}^{2}$ & \multicolumn{2}{|c|}{0.402} & \multicolumn{2}{|c|}{0.231} & \multicolumn{2}{|c|}{0.219} \\
\hline $\mathrm{F}$ & \multicolumn{2}{|c|}{85.53} & \multicolumn{2}{|c|}{121.56} & \multicolumn{2}{|c|}{95.31} \\
\hline
\end{tabular}

$\mathrm{N}=385,{ }^{*} p<0.05^{* *} p<01$.

\subsection{Hypotheses testing}

Hypotheses 1 to 3 in T1 and T2 hypothesized that job insecurity positively relates to work stress and negatively to job satisfaction and organizational commitment; And work stress negatively causes to job satisfaction and organizational commitment. Results show (please see Table 2 Time 1 and Time 2 that job insecurity is positively related to employee work stress for T1 $(b=0.885, p<0.001)$ and T2 $(b=0.233, p<0.001)$ supporting Hypothesis 1 . Work stress negatively related to job satisfaction for $\mathrm{T} 2$ $(b=0.353, p<0.01)$, for T2 $(b=0.412, p<0.01)$ and organizational commitment T1 $(b=465, p<0.01)$, T2 $(b=376, p<0.01)$ significantly supports Hypothesis 2. Organizational support positively related to job satisfaction at T1 $(b=0.068, p<0.01)$, T2 $(b=0.071, p<0.01)$ and organizational commitment T1 $(b=0.053, p<0.001), \mathrm{T} 2(b=0.068, p<0.001)$ providing significant support to Hypothesis 3.

Hypothesis 4 on organizational support suggested that it moderate the relationship between WS and a) 
Table 3

Results of Moderated mediation at Time 1

\begin{tabular}{lcccc}
\hline & \multicolumn{4}{c}{ Job satisfaction } \\
\hline Conditional indirect effect via WS & $B$ & SE & LLCI & ULCI \\
-ISD on organizational support & 0.7925 & 0.1254 & 0.5672 & 0.9876 \\
mean o organizational support & 0.4558 & 0.0382 & 0.3241 & 0.5204 \\
+ISD organizational support & 0.3343 & 0.0355 & 0.2559 & 0.4337 \\
Index of moderated mediation & Index & SE & LLCI & ULCI \\
Organizational support & 0.0289 & 0.0172 & 0.0034 & 0.0552 \\
\hline & & Organizational commitment & \\
\hline Conditional indirect effect via work stress & $B$ & SE & LLCI & ULCI \\
-ISD on organizational support & 0.5654 & 0.1365 & 0.3356 & 0.8452 \\
mean o organizational support & 0.2656 & 0.0541 & 0.1651 & 0.3672 \\
+ISD organizational support & 0.523 & 0.0456 & 0.4378 & 0.6274 \\
Index of moderated mediation & Index & SE & LLCI & ULCI \\
Organizational support & 0.0140 & 0.0102 & 0.0027 & 0.0382 \\
\hline
\end{tabular}

$\mathrm{N}=385,{ }^{*} p<05^{* *} p<01$.

Table 4

Results of Moderated mediation at Time 2

\begin{tabular}{|c|c|c|c|c|}
\hline \multirow[b]{2}{*}{ Conditional indirect effect via WS } & \multicolumn{4}{|c|}{ Job satisfaction } \\
\hline & $B$ & SE & LLCI & ULCI \\
\hline -ISD on organizational support & 0.6263 & 0.1505 & 0.3291 & 0.9223 \\
\hline mean o organizational support & 0.1232 & 0.0323 & 0.1510 & 0.0222 \\
\hline +ISD organizational support & 0.0565 & 0.0259 & 0.1353 & 0.0165 \\
\hline Index of moderated mediation & Index & SE & LLCI & ULCI \\
\hline \multirow[t]{2}{*}{ Organizational support } & 0.0092 & 0.0064 & 0.2102 & 0.0262 \\
\hline & \multicolumn{4}{|c|}{ Organizational commitment } \\
\hline Conditional indirect effect via WS & $B$ & SE & LLCI & ULCI \\
\hline -ISD on organizational support & 0.2561 & 0.1769 & 0.9353 & 0.3339 \\
\hline mean o organizational support & 0.0384 & 0.0293 & 0.2657 & 0.0210 \\
\hline +ISD organizational support & 0.0237 & 0.0232 & 0.0154 & 0.1570 \\
\hline Index of moderated mediation & Index & SE & LLCI & ULCI \\
\hline Organizational support & 0.0236 & 0.0114 & 0.0156 & 0.0293 \\
\hline
\end{tabular}

$\mathrm{N}=0.385,{ }^{*} p<0.05^{* *} p<0.01$.

JS, b) OC (please see Table 3 Time 1 and Time 2). The conditional positive relationship between perceived $\mathrm{JI}$ and work stress is stronger among those with low organizational support compared with those high in employability. Results show in Table 3 (Time 1) that the interaction between WS and JS, WS and OC is statistically significant, respectively, suggesting that the organizational support moderates WS's effect on JS and OC, respectively.

The interaction slopes of the relationships between WS and JS, and WS and OC at 3 points along the moderator's scale using a conventional 'pick a point approach' (Hayes, 2018). At -ISD on organizational support, the effect was positive and significant. At the mean organizational support, the effect of WS was significant for JS. At $a+$ ISD organizational support, WS was a significant positive predictor for JS. We see that slopes are becoming more positive as we move from low to high organizational support for both JS and OC. The index of moderated mediation provides a conditional indirect effect of organizational support moderating WS's indirect effect on JS and OC is statistically significant. Please see the following table.

We analyzed in Table 2 (Time 2) that the interaction between work stress and JS, work stress, and OC is 
statistically significant, respectively, suggesting that the organizational support moderates WS's effect on JS and OC. The interaction slopes of the relationships between WS and JS, and WS and OC at 3 points along the scale of the moderator using a conventional 'pick a point approach'(please see Table 4 Time 2). The index of moderated mediation provides a conditional indirect effect of organizational support moderating WS's indirect impact on JS and OC is statistically significant.

\section{Discussion and conclusion}

The unemployment rate in the midst of COVID-19 pandemic reached the highest points in various countries that was even higher from the great recession period $[64,65]$. The pandemic triggered stress among workers that caused significantly to people health and well-being. Hence, in this study, people well-being was investigated to see larger effects of the pandemic. The current study findings demonstrate job insecurity among workers and financial concern that are associated with stress and anxiety. Further, results suggest that greater job insecurity due to COVID-19 is related to more significant stress symptoms.

Drawing on the COR and organizational support theories, the present study hypothesized that job insecurity causes work stress and negatively led job outcomes. COR theory applied in this study as stress arises from COVID-19. The stress develops among employees because there is a loss of resources or threat of loss of resources in the form of job insecurity. Previously COR theory has been applied in various studies about work-family stress, burnout and stress. While COVID-19 unfortunately, a situation that provided us to study its effects on employee outcomes. As discussed in the results, the pandemic situation is threatening employees resources and eventually depletes their resources. It is a possible contribution that adds to the COR theory on account of COVID-19. Organizational support theory provides a valuable lens to study employees' trade outcomes and work efforts to cope with threatening position. Organizational support buffers between work stress and job outcomes presence. Very few studies are available using longitudinal data in the COVID-19 pandemic that have hypothesized and tested such effects. Many cross-sectional studies found job insecurity triggers work stress in COVID-19 pandemic [40, 66, 67]. The longitudinal results of the current study provided support and supplies increased understanding of the consequences of job insecurity by demonstrating how employees' perception regarding job insecurity affects their wellbeing.

The results regarding the effect of organizational support $\times$ work stress on both job satisfaction and organizational commitment are significant. It shows that workers' perception for organizational support is a resource gain that reduces work stress's negative effect. So organizational support reduces work stress, and it leads to increased job satisfaction and organizational commitment. Similarly, to Yeves et al., [67], in our study, the more chances of organizational support at the workplace, the higher the job satisfaction and organizational commitment. Greater organizational support lessens the effect of stress among people, leading to higher job satisfaction and organizational commitment. Significantly, our findings expand on these associations by demonstrating independent links between greater organizational support with lower stressful symptoms and higher satisfaction and commitment in COVID-19 times. Organizational support is kind of hope with the current state of the workforce due to the pandemic. It represents a factor that alleviates stress and consists of positive expectations about a valued outcome about the job. Further, these findings expand upon prior work on well-being during epidemics because the present study accounted for stress and anxiety symptoms, thus tearing apart the unique contribution of job insecurity and financial concern.

More specifically, the results demonstrate that employees feel the threat of a resource loss due to COVID-19, and they need to figure out changes and action plans they can take to offset the effects of a pandemic. In this regard, they look at their finances and reduce their discretionary spending so that they have some resource gain in these times. The emotional impact of losing a job is the most daring thing an employee experience in a career. While COVID-19 is not an unusual time, increased organizational support is needed in these times. Hence, organizational support is a signalling mechanism and it decreases difficulties in critical times. This study has some limitations. First, the data were collected through a convenience sampling method, so results can not be generalized to the population as a whole. Second, we collected data only from MNCs' (i.e. food and beverages) operating in Pakistan, so it cuts out a large part of populations in other sectors of the said companies. Finally, other moderating factors may influence the proposed relations, such as perceived employability not explored by the current study. Future studies may 
focus on exploring such other factors that can affect the relations under consideration.

This study examined perceived job insecurity as an antecedent of adverse job outcomes by applying assumptions of conservation of resources and organizational support theories. Besides, we investigated the role of organizational support as a possible coping mechanism. In brief, we argued that job insecurity cause stress, affecting employee psychological well-being and work outcomes. In contrast, workers received organizational support as a resource gain as an individual characteristic that makes them less sensitive to perceived job insecurity.

\section{References}

[1] Chirumbolo A, Callea A, Urbini F. Job insecurity and performance in public and private sectors: a moderated mediation model. J Organ Eff People Perform. 2020;7(2):237-253. DOI: 10.1108/JOEPP-02-2020-0021

[2] Darvishmotevali M, Arasli H, Kilic H. Effect of job insecurity on frontline employee's performance. Int J Contemp Hosp Manag. 2017;29(6):1724-1744. DOI: 10.1108/IJCHM-12-2015-0683

[3] Blomqvist S, Xu T, Persitera P, L $\backslash$ a astad L, Hanson LLM. Associations between cognitive and affective job insecurity and incident purchase of psychotropic drugs: A prospective cohort study of Swedish employees. J Affect Disord. 2020;266:215-22.

[4] Gallie D, Felstead A, Green F, Inanc H. The hidden face of job insecurity. Work Employ Soc. 2017;31(1):36-53.

[5] Lee C, Huang G-H, Ashford SJ. Job insecurity and the changing workplace: Recent developments and the future trends in job insecurity research. Annual Review of Organizational Psychology and Organizational Behavior. 2018;5(1):335-359.

[6] Shoss MK. Job insecurity: An integrative review and agenda for future research. J Manag. 2017;43(6):1911-39.

[7] Jun D, O'Leary S, McPhail SM, Johnston V. Job strain and psychological distress in office workers: The role of coping. Work. 2019;64(1):55-65.

[8] De Cuyper N, Schreurs B, De Witte H, Selenko E. Impact of job insecurity on job performance introduction. Career Dev Int. 2020;25(3):221-228. DOI: 10.1108/CDI-06-2020-332

[9] Darvishmotevali M, Ali F. Job insecurity, subjective wellbeing and job performance: The moderating role of psychological capital. Int J Hosp Manag. 2020;87:102462.

[10] Jiang L, Lavaysse LM. Cognitive and affective job insecurity: A meta-analysis and a primary study. J Manag. 2018; 44(6):2307-42.

[11] Naeem K, Dapeng L, Durrani DK, Anjum MA. Highperformance work practices versus work-role ambiguity. Hum Syst Manag. 2019;38(2):141-8.

[12] Chakraborty I, Maity P. COVID-19 outbreak: Migration, effects on society, global environment and prevention. Sci Total Environ. 2020;138882.
[13] McKibbin WJ, Fernando R. The global macroeconomic impacts of COVID-19: Seven scenarios. Asian Economic Papers. 2021;20(2):1-30. DOI: 10.1162/asep_a_00796

[14] Sahu P. Closure of universities due to Coronavirus Disease 2019 (COVID-19): impact on education and mental health of students and academic staff. Cureus. 2020;12(4).

[15] Lee J-H, Hwang J, Lee K-S. Job satisfaction and job-related stress among nurses: The moderating effect of mindfulness. Work. 2019;62(1):87-95.

[16] Burgard SA, Brand JE, House JS. Perceived job insecurity and worker health in the United States. Soc Sci Med. 2009;69(5):777-85.

[17] Dekker SW, Schaufeli WB. The effects of job insecurity on psychological health and withdrawal: A longitudinal study. Aust Psychol. 1995;30(1):57-63.

[18] Burchell B, Ladipo D, Wilkinson F. Job insecurity and work intensification. Routledge; 2001.

[19] De Witte H. Job insecurity: Review of the international literature on definitions, prevalence, antecedents and consequences. SA J Ind Psychol. 2005;31(4):1-6.

[20] Jiskani SN, Bhatti KR, Ahmed S. Measuring job satisfaction level of government sector employees: a case of bureau of statistics, government of Sindh, Pakistan. J Manag Soc Sci. 2011;7(1):19-26.

[21] Ahmed S, Khan MA, Memon ZA. Organizational Culture and its Impact on Employee Career Progression in Public Sector Organizations in Pakistan. IBT J Bus Stud JBS. 2014;10(2).

[22] Hobfoll SE. The ecology of stress. Taylor \& Francis; 1988.

[23] Eisenberger R, Fasolo P, Davis-LaMastro V. Perceived organizational support and employee diligence, commitment, and innovation. J Appl Psychol. 1990;75(1):51.

[24] Hobfoll SE, Halbesleben J, Neveu J-P, Westman M. Conservation of resources in the organizational context: The reality of resources and their consequences. Annu Rev Organ Psychol Organ Behav. 2018;5:103-28.

[25] Eisenberger R, Malone GP, Presson WD. Optimizing perceived organizational support to enhance employee engagement. Soc Hum Resour Manag Soc Ind Organ Psychol. 2016;2:22.

[26] Kirkland JE, Eisenberger R, Lewis BA, Wen X. Perceived organizational support, anticipated change in organizational support, and commitment. In: Academy of Management Proceedings. Academy of Management Briarcliff Manor, NY 10510; 2017. pp. 11246.

[27] Vardaman JM, Allen DG, Otondo RF, Hancock JI, Shore LM, Rogers BL. Social comparisons and organizational support: Implications for commitment and retention. Hum Relat. 2016;69(7):1483-505.

[28] Chen T, Hao S, Ding K, Feng X, Li G, Liang X. The impact of organizational support on employee performance. Empl Relat Int J. 2020;

[29] Dai Y-D, Hou Y-H, Chen K-Y, Zhuang W-L. To help or not to help: antecedents of hotel employees' organizational citizenship behavior. Int $\mathbf{J}$ Contemp Hosp Manag. 2018;30(3):1293-1313. DOI: 10.1108/IJCHM-032016-0160

[30] Maan AT, Abid G, Butt TH, Ashfaq F, Ahmed S. Perceived organizational support and job satisfaction: a moderated 
mediation model of proactive personality and psychological empowerment. Future Bus J. 2020;6(1):1-12.

[31] Soomro SA, Roques O, Ali A. Exposure to Terror and Employees' Behaviour; Rumination as a Mediator and POS as a Moderator. In: Academy of Management Proceedings. Academy of Management Briarcliff Manor, NY 10510; 2018. pp. 11887.

[32] Charoensukmongkol P, Moqbel M, Gutierrez-Wirsching S, Shankar R. The role of coworker and supervisor support on job burnout and job satisfaction. J Adv Manag Res. 2016;13(1). DOI: 10.1108/JAMR-06-2014-0037

[33] Maertz Jr CP, Griffeth RW, Campbell NS, Allen DG. The effects of perceived organizational support and perceived supervisor support on employee turnover. J Organ Behav Int J Ind Occup Organ Psychol Behav. 2007;28(8): 1059-75.

[34] van Vuuren T, de Jong JP, Smulders PG. The association between subjective job insecurity and job performance across different employment groups: Evidence from a representative sample from the Netherlands. Career Dev Int. 2019;25(3):229-246. DOI: 10.1108/CDI-05-2018-0155

[35] Greenhalgh L, Rosenblatt Z. Job insecurity: Toward conceptual clarity. Acad Manage Rev. 1984;9(3):438-48.

[36] Greenhalgh L, Rosenblatt Z. Evolution of research on job insecurity. Int Stud Manag Organ. 2010;40(1):6-19.

[37] Karapinar PB, Camgöz SM, Ekmekci OT. Reviewing measurement instruments in job insecurity research: perceived job insecurity and the gender lens perspective. In: Handbook of Research Methods on the Quality of Working Lives. Edward Elgar Publishing; 2019.

[38] Parent-Lamarche A, Marchand A. Work stress, personality traits, and cortisol secretion: Testing a model for job burnout. Work. 2018;60(3):485-97.

[39] Nam T. Technology usage, expected job sustainability, and perceived job insecurity. Technol Forecast Soc Change. 2019; 138:155-65.

[40] Huang G, Wellman N, Ashford SJ, Lee C, Wang L. Deviance and exit: The organizational costs of job insecurity and moral disengagement. J Appl Psychol. 2017;102(1):26.

[41] Soomro SA, Kundi YM, Kamran M. Antecedents of Workplace Deviance: Role of Job Insecurity, Work Stress, and Ethical Work Climate. Probl Zarzadzania. 2019;17(6).

[42] Tison GH, Avram R, Kuhar P, Abreau S, Marcus GM, Pletcher MJ, et al. Worldwide effect of COVID-19 on physical activity: a descriptive study. Ann Intern Med. 2020;173(9):767-770.

[43] DePietro A. Here'sa look at the impact of Coronavirus (COVID-19) on colleges and universities in the US. Forbes April. 2020;30.

[44] Borg I, Elizur D. Job insecurity: Correlates, moderators and measurement. Int J Manpow. 1992;13(2):13-26. DOI: $10.1108 / 01437729210010210$

[45] Abbas W, Wu W. Employee innovativeness, fairness and organizational support: An empirical assessment. Hum Syst Manag. 2019;38(2):169-77.

[46] Abou Hashish EA. Relationship between ethical work climate and nurses' perception of organizational support, commitment, job satisfaction and turnover intent. Nurs Ethics. 2017;24(2):151-66.
[47] Kurtessis JN, Eisenberger R, Ford MT, Buffardi LC, Stewart KA, Adis CS. Perceived organizational support: A meta-analytic evaluation of organizational support theory. J Manag. 2017;43(6):1854-84.

[48] Shanock LR, Eisenberger R, Heggestad ED, Malone G, Clark L, Dunn AM, et al. Treating employees well: The value of organizational support theory in human resource management. Psychol-Manag J. 2019;22(3-4):168-191. DOI: $10.1037 / \mathrm{mgr} 0000088$

[49] Khan NH, Ju Y, Baloch MA, Uddin I. Pharma macroenvironmental risks and organizational self-development. Hum Syst Manag. 2019;38(2):149-58.

[50] Kumar N, Che Rose R. The impact of knowledge sharing and Islamic work ethic on innovation capability. Cross Cult Manag Int J. 2012;19(2):142-65.

[51] Soomro SA, Roques O, Ali A. Fear of terror and employees' behaviour in terrorist-ridden areas. J Aggress Confl Peace Res. 2020;12(3):125-137. DOI: 10.1108/JACPR-04-20200489

[52] Caesens G, Stinglhamber F, Demoulin S, De Wilde M. Perceived organizational support and employees' well-being: The mediating role of organizational dehumanization. Eur J Work Organ Psychol. 2017;26(4):527-40.

[53] Gigliotti R, Vardaman J, Marshall DR, Gonzalez K. The role of perceived organizational support in individual change readiness. J Change Manag. 2019;19(2):86-100.

[54] Bolger N, Davis A, Rafaeli E. Diary methods: Capturing life as it is lived. Annu Rev Psychol. 2003;54(1):579-616.

[55] Dormann C, Zapf D. Social stressors at work, irritation, and depressive symptoms: Accounting for unmeasured third variables in a multi-wave study. J Occup Organ Psychol. 2002;75(1):33-58.

[56] Kundi YM, Aboramadan M, Elhamalawi EM, Shahid S. Employee psychological well-being and job performance: exploring mediating and moderating mechanisms. Int $\mathrm{J}$ Organ Anal. 2020;29(3):736-754. DOI: 10.1108/IJOA-052020-2204

[57] Netemeyer RG, Maxham III JG, Pullig C. Conflicts in the work-family interface: Links to job stress, customer service employee performance, and customer purchase intent. J Mark. 2005;69(2):130-43.

[58] Stajkovic AD, Luthans F. Self-efficacy and workrelated performance: A meta-analysis. Psychol Bull. 1998;124(2):240.

[59] Allen NJ, Meyer JP. Organizational commitment: evidence of career stage effects? J Bus Res. 1993;26(1):49-61.

[60] Moksnes UK, Espnes GA. Self-esteem and life satisfaction in adolescents-gender and age as potential moderators. Qual Life Res. 2013;22(10):2921-8.

[61] Schulze D, Pohl S. Finding clusters of measurement invariant items for continuous covariates. Struct Equ Model Multidiscip J. 2020;1-10.

[62] Podsakoff PM, MacKenzie SB, Podsakoff NP. Sources of method bias in social science research and recommendations on how to control it. Annu Rev Psychol. 2012;63:539-69.

[63] Hayes AF, Matthes J. Computational procedures for probing interactions in OLS and logistic regression: SPSS and SAS implementations. Behav Res Methods. 2009;41(3):924-36. 
[64] Broström L. The neglected female unemployment in Sweden during the Great Depression. Labor Hist. 2019;60(6): 704-15.

[65] Mathy GP. Hysteresis and persistent long-term unemployment: the American Beveridge Curve of the Great Depression and World War II. Cliometrica. 2018;12(1): 127-52.
[66] Wu C-H, Wang Y, Parker SK, Griffin MA. Effects of chronic job insecurity on Big Five personality change. J Appl Psychol. 2020;105(11):1308-1326. DOI: 10.1037/ap10000488

[67] Yeves J, Bargsted M, Cortes L, Merino C, Cavada G. Age and perceived employability as moderators of job insecurity and job satisfaction: A moderated moderation model. Front Psychol. 2019;10:799. 